\title{
Epidemiology and risk factors in CKD patients with pulmonary hypertension: a retrospective study
}

\author{
Qian Zhang, Le Wang, Hongbing Zeng, Yongman Lv ${ }^{\dagger}$ and Yi Huang ${ }^{* \dagger}$
}

\begin{abstract}
Background: Pulmonary hypertension $(\mathrm{PH})$ is a rare disease often associated with high mortality and is recently recognized as a common complication secondary to chronic kidney disease (CKD). Epidemiological data for this disorder across the spectrum of CKD is poorly understood.

Methods: We retrospectively analyzed 705 CKD patients with complete clinical records from July 2013 to September 2015. All the patients were estimated by echocardiography and PH was defined as pulmonary artery systolic pressure (PASP) $>35 \mathrm{mmHg}$. The prevalence of PH in CKD patients was investigated, and their association was evaluated with a logistic regression model.

Results: The overall prevalence of PH was 47.38\%, in which mild, moderate and severe PH accounted for 22.13, 15.04 and $10.21 \%$, respectively. The prevalence of PH in CKD stage $1-5$ was $14.29,33.33,38.89,40.91$ and $64.47 \%$. The prevalence of total PH was 57.63\% in PD patients and 58.82\% in HD patients. Compared with the non-dialysis patients, the prevalence of PH was much higher in patients receiving dialysis. Body mass index (BMI), hemoglobin, triglyceride (TG), proteinuria, parathyroid hormone (PTH) and estimated glomerular filtration rate (eGFR) were independent risk factors of PH in CKD patients.

Conclusions: The prevalence of $\mathrm{PH}$ is increased with the deterioration of renal function, however, which has no direct relation to the severity of PH. PH occurs more frequently in dialysis patients. Higher BMI and TG, more sever anemia, proteinuria and secondary hyperparathyroidism, poor renal dysfunction predict predict the more prevalence of $\mathrm{PH}$ in CKD patients.
\end{abstract}

Keywords: Pulmonary hypertension, Chronic kidney disease, Prevalence, Risk factors

\section{Background}

Pulmonary hypertension $(\mathrm{PH})$ is primarily a disease of the small arteries of the pulmonary vasculature, with progressive obliteration leading to the increases in pulmonary vascular resistance (PVR) and pulmonary arterial pressure (PAP) that characterize the disease [1]. The increased PVR often leads to right ventricular failure associated with high mortality [2]. The mechanisms responsible for $\mathrm{PH}$ still remain incompletely understood. Many studies have shown that $\mathrm{PH}$ occurred frequently in patients with chronic kidney disease (CKD) and some

\footnotetext{
* Correspondence: hann5683@163.com

${ }^{\dagger}$ Equal contributors

Division of Nephrology, Department of Internal Medicine, Tongji Hospital,

Tongji Medical College, Huazhong University of Science and Technology,

Wuhan, Hubei, People's Republic of China
}

of them have explored the relation between CKD and PH $[3,4]$. PH in patients with CKD may be induced and aggravated by left ventricular disorders and risk factors typical of CKD, including volume overload, an arteriovenous fistula, sleep-disordered breathing, exposure to dialysis membranes, endothelial dysfunction, vascular calcification and stiffening, and severe anemia [3]. A review reported that the prevalence of $\mathrm{PH}$ ranged from 9-39\% in individuals with stage 5 CKD, $18.8-68.8 \%$ in hemodialysis patients, and $0-42 \%$ in patients on peritoneal dialysis therapy [3]. However, few epidemiologic data are available for earlier stages of CKD. Based on a retrospective analysis of 705 CKD patients, this study aims to investigate the epidemiology and prevalence of $\mathrm{PH}$ in

(c) The Author(s). 2018 Open Access This article is distributed under the terms of the Creative Commons Attribution 4.0 International License (http://creativecommons.org/licenses/by/4.0/), which permits unrestricted use, distribution, and reproduction in any medium, provided you give appropriate credit to the original author(s) and the source, provide a link to the Creative Commons license, and indicate if changes were made. The Creative Commons Public Domain Dedication waiver (http://creativecommons.org/publicdomain/zero/1.0/) applies to the data made available in this article, unless otherwise stated. 
different stages of CKD and to determinate the related risk factors of $\mathrm{PH}$ in CKD.

\section{Methods \\ Participants}

The retrospective study was performed in the renal division of Tongji Hospital in China. All patients with CKD who received echocardiography were included from July 2013 to September 2015. The etiologies for CKD included glomerulonephritis, diabetic nephropathy, hypertensive nephropathy, lupus nephritis, polycystic kidney disease and others. The inclusion criteria were as follows: (1) The age of the patients was more than 18 years old; (2) All patients were diagnosed as CKD according to $\mathrm{K} / \mathrm{DOQI}$ guidelines, including peritoneal dialysis (PD) and hemodialysis (HD) patients; (3) All patients had complete clinical data. Patients were excluded as follows: (1) Connective tissue disease except for lupus, HIV infection, congenital heart disease, acute heart failure, portal hypertension and pulmonary veno-occlusive disease, drugs and toxins; (2) COPD, interstitial lung disease and sleep apnea; (3) Obstructive of pulmonary arterial vessels by thromboemboli, tumors, or foreign bodies.

\section{Clinical and laboratory data collection}

Patient data on baseline characteristics (age, gender, BMI, medication used), etiology of CKD, laboratory tests and hemodynamics were recorded. Two-dimensional (2D)-guided M-mode echocardiography were performed by experienced technicians with an Acuson Sequoia, C256 (Mountain View, CA, USA) ultrasound machine. A tricuspid systolic jet was recorded from the parasternal or apical window with the continuous wave Doppler probe. Pulmonary artery systolic pressure (PASP) was estimated by a modified Bernoulli equation: PASP $=$ $4 \times$ (tricuspid systolic jet) ${ }^{2}+10 \mathrm{mmHg}$ (estimated right atrial pressure) $[5,6]$. $\mathrm{PH}$ was defined as a PASP > $35 \mathrm{mmHg}[7,8]$. The severity of $\mathrm{PH}$ was categorized according to the SPAP as follows: mild (35-45 mmHg), moderate $(45-60 \mathrm{mmHg})$ and severe $(>60 \mathrm{mmHg})$ [9].

\section{Data analysis}

All statistical analysis was performed using the SPSS 18.0 software. The categorical data were reported as numbers and the differences were tested with the $x^{2}$ test. Continuous variables were summarized as means \pm standard deviation (SD). Differences among groups were compared with Student's $t$ test for the normally distributed variables and Mann-Whitney $U$ test for the nonnormally distributed variables. Descriptive statistics related to the prevalence of $\mathrm{PH}$ were calculated with logistic regression analysis. The $P$-values reported were twosided and taken to be significant at $<0.05$.

\section{Results}

From July 2013 to September 2015, CKD patients from our renal division who received echocardiography were recruited. A total of 705 patients satisfied the inclusion criteria. There were 400 males and 305 females with a mean age of $48.97 \pm 16.74$ years. Common cause of CKD included glomerulonephritis (68.37\%), diabetic nephropathy (14.75\%), hypertensive nephropathy (8.09\%), lupus nephritis $(1.84 \%)$, polycystic kidney disease $(2.84 \%)$ and others (4.11\%). The baseline demographic, clinical, laboratory and hemodynamic characteristics of the patients in different stages of CKD were summarized in Table 1.

\section{Epidemiology of PH in different stages of CKD}

The overall prevalence of $\mathrm{PH}$ was $47.38 \%$ (334/705), in which mild, moderate and severe $\mathrm{PH}$ accounted for 22.13 , 15.04 and $10.21 \%$, respectively. The prevalence of $\mathrm{PH}$ in CKD stage $1-5$ was $14.29 \%(12 / 84), 33.33 \%(21 / 63)$, $38.89 \%$ (42/108), 40.91\% (54/132) and 64.47\% (205/318) (Fig. 1). With the deterioration of renal function, the incidence of $\mathrm{PH}$ was increased gradually. However, the severity of $\mathrm{PH}$ seemed to have no regular distribution.

Among all the CKD patients, 331 ones have received dialysis. Compared with the non-dialysis patients, the prevalence of $\mathrm{PH}$ was much higher in patients received dialysis. In dialysis patients, mild-to-moderate $\mathrm{PH}$ appeared frequently. However, there was no difference in the incidence of severe $\mathrm{PH}$ between dialysis patients and non-dialysis patients (Fig. 2).

Among all the dialysis patients, there were 59 for PD and 272 for HD. The prevalence of $\mathrm{PH}$ was $57.63 \%$ in PD patients and $58.82 \%$ in HD patients. However, the incidence of $\mathrm{PH}$ in $\mathrm{PD}$ and $\mathrm{HD}$ patients was different according to the severity of $\mathrm{PH}$. The prevalence of moderate and severe $\mathrm{PH}$ was 5.08 and $25.42 \%$ in PD patients, separately. However, the prevalence of moderate and severe $\mathrm{PH}$ was 23.16 and $8.09 \%$ in $\mathrm{HD}$ patients, separately. Interestingly, the incidence was no difference in mild $\mathrm{PH}$ between PD and HD patients (Fig. 3).

\section{Determinants of PH in CKD patients}

The baseline demographic, clinical, laboratory, and hemodynamic characteristics of the study population by $\mathrm{PH}$ severity were shown in Table 2 . Compared with the non- $\mathrm{PH}$ patients, the patients with $\mathrm{PH}$ had lower hemoglobin, albumin, complement 3, estimated glomerular filtration rate (eGFR), left ventricular ejection fraction (LVEF) levels and higher body mass index (BMI), triglyceride (TG), parathyroid hormone (PTH), proteinuria, blood pressure (systolic and diastolic) and time of dialysis. With $\mathrm{PH}$ as dependent variable and the above factors as covariates, only six variables, BMI, hemoglobin, TG, proteinuria, PTH and eGFR, were independent risk factors in the prevalence of $\mathrm{PH}$ in $\mathrm{CKD}$ 
Table 1 Baseline demographic, clinical, laboratory, and hemodynamic characteristics of the study population by eGFR

\begin{tabular}{|c|c|c|c|c|c|c|}
\hline & All & CKD1 & CKD2 & CKD3 & CKD4 & CKD5 \\
\hline No. of patients & 705 & 84 & 63 & 108 & 132 & 318 \\
\hline Age (years) & $48.12 \pm 15.02$ & $39.50 \pm 15.59$ & $45.49 \pm 15.10$ & $49.52 \pm 15.15$ & $51.54 \pm 15.30$ & $46.44 \pm 14.63$ \\
\hline \multicolumn{7}{|l|}{ Gender } \\
\hline Male, n (\%) & $390(55.32 \%)$ & $44(52.38 \%)$ & $25(39.68 \%)$ & 75 (69.44\%) & 85 (64.39\%) & $161(52.83 \%)$ \\
\hline Female, n (\%) & $315(44.68 \%)$ & $40(47.62 \%)$ & $38(60.32 \%)$ & $33(30.56 \%)$ & 47 (35.61\%) & $157(47.17 \%)$ \\
\hline BMI $\left(\mathrm{kg} / \mathrm{m}^{2}\right)$ & $22.32 \pm 4.45$ & $21.88 \pm 4.08$ & $22.43 \pm 4.58$ & $22.04 \pm 4.56$ & $22.19 \pm 3.88$ & $22.56 \pm 4.70$ \\
\hline \multicolumn{7}{|l|}{ Etiology of CKD, n (\%) } \\
\hline Glomerulonephritis & $481(68.23 \%)$ & 65 (77.38\%) & 39 (61.90\%) & 79 (73.15\%) & $83(62.88 \%)$ & $215(67.61 \%)$ \\
\hline Diabetic nephropathy & $104(14.75 \%)$ & $9(10.71 \%)$ & $13(20.63 \%)$ & $12(11.11 \%)$ & 25 (18.94\%) & $45(14.15 \%)$ \\
\hline Hypertensive nephropathy & 57 (8.09\%) & $4(4.76 \%)$ & $6(9.52 \%)$ & $9(8.33 \%)$ & $13(9.85 \%)$ & $25(7.86 \%)$ \\
\hline Lupus nephritis & $14(1.99 \%)$ & $0(0 \%)$ & $1(1.59 \%)$ & $1(0.93 \%)$ & $5(3.79 \%)$ & $7(2.20 \%)$ \\
\hline Polycystic kidney disease & $20(2.84 \%)$ & $3(3.57 \%)$ & $1(1.59 \%)$ & $3(2.78 \%)$ & $1(0.76 \%)$ & $12(3.77 \%)$ \\
\hline Others & $29(4.11 \%)$ & $3(3.57 \%)$ & $3(4.76 \%)$ & $4(3.70 \%)$ & $5(3.79 \%)$ & $14(4.40 \%)$ \\
\hline \multicolumn{7}{|l|}{ Medications, n (\%) } \\
\hline ACEI or ARB & $294(41.70 \%)$ & 49 (58.33\%) & $16(25.40 \%)$ & $0(0 \%)$ & $51(38.64 \%)$ & 178 (55.97\%) \\
\hline Diuretics & $88(12.48 \%)$ & $0(0 \%)$ & $0(0 \%)$ & $28(25.93 \%)$ & 24 (18.18\%) & $36(11.32 \%)$ \\
\hline $\mathrm{CCB}$ & 407 (57.73\%) & $21(25 \%)$ & $21(25 \%)$ & 64 (59.26\%) & 92 (69.70\%) & 209 (65.72\%) \\
\hline$\beta$-blocker & $285(40.43 \%)$ & $13(15.48 \%)$ & $16(25.40 \%)$ & 43 (39.81\%) & 64 (48.48\%) & 149 (46.86\%) \\
\hline a-blocker & $18(2.55 \%)$ & $0(0 \%)$ & $0(0 \%)$ & $2(1.85 \%)$ & $5(3.79 \%)$ & $11(3.46 \%)$ \\
\hline Digoxin & $14(1.99 \%)$ & $0(0 \%)$ & $0(0 \%)$ & $0(0 \%)$ & $0(0 \%)$ & $14(4.40 \%)$ \\
\hline Warfarin & $26(3.69 \%)$ & $0(0 \%)$ & $0(0 \%)$ & $12(11.11 \%)$ & $0(0 \%)$ & $14(4.40 \%)$ \\
\hline Prostacyclin & 247 (35.04\%) & $0(0 \%)$ & 12 (19.05\%) & $76(70.37 \%)$ & $82(62.12 \%)$ & 77 (24.21\%) \\
\hline \multicolumn{7}{|l|}{ Laboratory tests } \\
\hline $\mathrm{Hb}(\mathrm{g} / \mathrm{L})$ & $94.19 \pm 23.46$ & $103.66 \pm 20.54$ & $100.68 \pm 21.29$ & $103.05 \pm 26.33$ & $94.64 \pm 23.56$ & $87.22 \pm 21.26$ \\
\hline ALB $(g / L)$ & $34.75 \pm 5.68$ & $35.60 \pm 5.07$ & $34.39 \pm 5.26$ & $34.80 \pm 5.59$ & $34.27 \pm 5.25$ & $34.78 \pm 6.11$ \\
\hline $\mathrm{TC}(\mathrm{mmol} / \mathrm{L})$ & $4.37 \pm 1.16$ & $4.41 \pm 0.98$ & $4.50 \pm 1.28$ & $4.44 \pm 1.30$ & $4.12 \pm 0.93$ & $4.41 \pm 1.21$ \\
\hline $\mathrm{TG}(\mathrm{mmol} / \mathrm{L})$ & $1.68 \pm 1.10$ & $1.52 \pm 0.82$ & $1.53 \pm 0.80$ & $1.66 \pm 1.03$ & $1.82 \pm 1.26$ & $1.70 \pm 1.17$ \\
\hline Proteinuria (mg/24 h) & $1783.13 \pm 1233.31$ & $1387.64 \pm 1016.40$ & $1586.44 \pm 1122.68$ & $1543.20 \pm 1207.24$ & $1699.50 \pm 1158.92$ & $2042.75 \pm 1294.12$ \\
\hline $\mathrm{Ca}(\mathrm{mmol} / \mathrm{L})$ & $2.17 \pm 0.19$ & $2.20 \pm 0.11$ & $2.16 \pm 0.11$ & $2.27 \pm 0.12$ & $2.22 \pm 0.14$ & $2.22 \pm 0.24$ \\
\hline $\mathrm{P}(\mathrm{mmol} / \mathrm{L})$ & $1.41 \pm 0.52$ & $0.99 \pm 0.12$ & $1.04 \pm 0.13$ & $1.11 \pm 0.13$ & $1.25 \pm 0.23$ & $1.76 \pm 0.57$ \\
\hline PTH (pg/ml) & $326.20 \pm 180.71$ & $271.98 \pm 123.31$ & $334.10 \pm 182.36$ & $290.55 \pm 153.09$ & $320.75 \pm 146.67$ & $353.33 \pm 207.99$ \\
\hline Ferritin (ng/ml) & $350.27 \pm 192.52$ & $319.08 \pm 95.40$ & $331.24 \pm 92.25$ & $366.82 \pm 258.77$ & $354.95 \pm 132.96$ & $354.72 \pm 218.88$ \\
\hline $\mathrm{SI}(\mu \mathrm{mol} / \mathrm{L})$ & $12.38 \pm 5.62$ & $12.74 \pm 4.88$ & $12.36 \pm 5.62$ & $12.49 \pm 5.36$ & $11.60 \pm 5.69$ & $12.58 \pm 5.86$ \\
\hline C3 (g/L) & $0.96 \pm 0.29$ & $1.01 \pm 0.32$ & $0.96 \pm 0.29$ & $0.98 \pm 0.31$ & $0.93 \pm 0.31$ & $0.94 \pm 0.27$ \\
\hline \multicolumn{7}{|l|}{ Hemodynamics } \\
\hline $\mathrm{SBP}(\mathrm{mmHg})$ & $141.24 \pm 14.14$ & $137.43 \pm 12.18$ & $138.30 \pm 9.89$ & $138.45 \pm 16.09$ & $142.33 \pm 14.78$ & $143.32 \pm 13.97$ \\
\hline $\mathrm{DBP}(\mathrm{mmHg})$ & $85.44 \pm 9.80$ & $82.41 \pm 9.21$ & $84.48 \pm 8.34$ & $84.43 \pm 10.35$ & $84.28 \pm 10.08$ & $87.26 \pm 9.62$ \\
\hline PASP $(\mathrm{mmHg})$ & $39.39 \pm 13.86$ & $32.40 \pm 9.35$ & $38.38 \pm 14.66$ & $38.04 \pm 13.69$ & $38.86 \pm 13.78$ & $42.13 \pm 14.09$ \\
\hline LVEF (\%) & $62.05 \pm 10.04$ & $65.08 \pm 10.02$ & $64.81 \pm 6.49$ & $63.92 \pm 8.46$ & $61.45 \pm 9.88$ & $60.31 \pm 10.79$ \\
\hline
\end{tabular}

eGFR estimated glomerular filtration rate, CKD chronic kidney disease, $B M I$ body mass index, $A C E l$ angiotensin converting enzyme inhibitor, $A R B$ angiotensin receptor blocker, $C C B$ calcium channel blocker, $H b$ hemoglobin, $A L B$ albumin, $T C$ total cholesterol, $T G$ triglyceride, $P T H$ parathyroid hormone, $S /$ serum iron, $S B P$ systolic blood pressure, DBP diastolic blood pressure, PASP pulmonary artery systolic pressure, LVEF left ventricular ejection fraction. Results are reported as means \pm standard deviation 


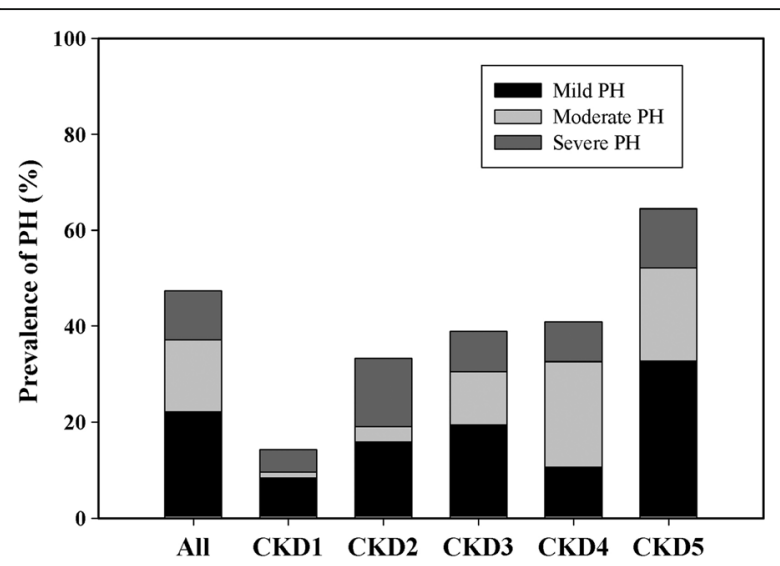

Fig. 1 Prevalence of mild, moderate and severe $\mathrm{PH}$ in different stages of CKD patients

patients. The multivariate determinants of prevalence of $\mathrm{PH}$ were shown in Table 3.

\section{Discussion}

Pulmonary hypertension $(\mathrm{PH})$ is a disease of the progressive condition characterized by elevated pulmonary arterial pressures and pulmonary vascular resistance leading to right ventricular failure [10]. The pulmonary vascular injury underlying $\mathrm{PH}$ occurs in an idiopathic form or in association with other disease states or exposures and is probably a final common response to environmental or disease-related inciting factors coupled with genetically determined susceptibilities [11]. Many studies have shown that $\mathrm{PH}$ occurred frequently in patients with chronic kidney disease (CKD), especially in end-stage renal disease (ESRD) patients. However, few epidemiologic data are available to investigate the prevalence of $\mathrm{PH}$ prior to CKD stage 4/5. In our study, we observed the prevalence of $\mathrm{PH}$ in different stages of CKD patients,

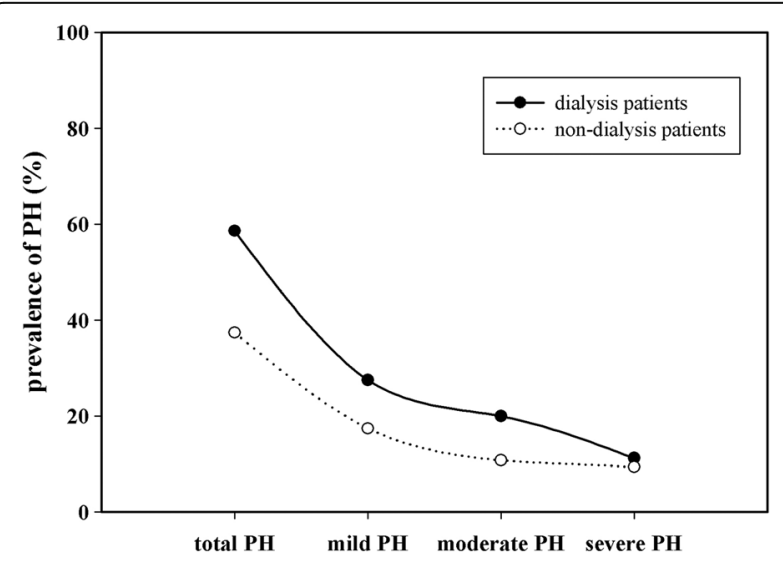

Fig. 2 Prevalence of mild, moderate and severe $\mathrm{PH}$ in dialysis patients. Compared with the non-dialysis patients, the prevalence of $\mathrm{PH}$ was much higher in patients received dialysis

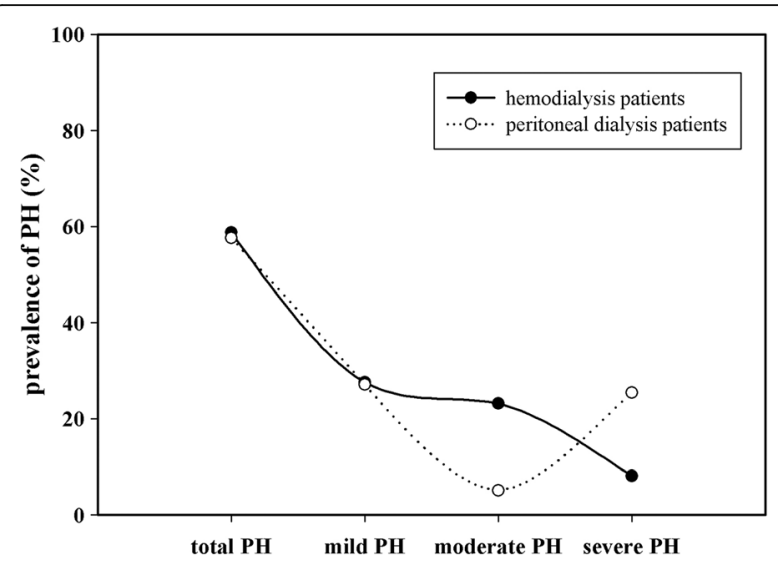

Fig. 3 Prevalence of mild, moderate and severe PH in $\mathrm{HD}$ and PD patients

including HD and PD patients, and investigated the relation between $\mathrm{PH}$ and CKD.

Some researches have reported that the prevalence of $\mathrm{PH}$ ranged from 9-39\% in individuals with stage 5 CKD, $18.8-68.8 \%$ in hemodialysis patients, and $0-42 \%$ in patients on peritoneal dialysis therapy [3]. Wei Shi et al. reported that the prevalence of PH in CKD Stage 1-5D was $2.2,6.7,7.9,15.2,20.0$ and $37.5 \%$, respectively [12]. In our study, the overall prevalence of $\mathrm{PH}$ was $47.38 \%$ in the CKD population. The prevalence of $\mathrm{PH}$ in CKD stage $1-5$ was $14.29,33.33,38.89,40.91$ and $64.47 \%$. Prevalence estimates are variable due to several possible reasons. First, varying definitions of $\mathrm{PH}$ might account for varying prevalence estimates. Second, variable degrees of volume overload might also confound the prevalence. Third, some of CKD patients lack of echocardiography data were excluded.

We found that the prevalence of $\mathrm{PH}$ was increased with the deterioration of renal function, however, which had no direct relation to the severity of $\mathrm{PH}$. Moderateto-severe $\mathrm{PH}$ might occur in any stages of CKD, indicating that $\mathrm{PH}$ was a multi -factorial disorder in ESRD. However, we found that most of $\mathrm{PH}$ patients in CKD stage 1-2 were asymptomatic and had no records of any specific therapy for PH. Prostacyclin has been the mainstay of $\mathrm{PH}$ treatment for more than a decade. And it appeared to have cytoprotective and antiproliferative activities, which was also used for the treatment of CKD [10]. Therefore, the distribution of mild-moderate-severe $\mathrm{PH}$ in CKD stage 3-5 might be varied due to prostacyclin. The Doppler-estimated PASP was much higher in patients who received dialysis. It had no difference in the overall prevalence of $\mathrm{PH}$ between $\mathrm{HD}$ and PD patients. However, the distribution of moderate-to-severe $\mathrm{PH}$ varied differently in dialysis patients.

The baseline demographic, clinical, laboratory, and hemodynamic characteristics of patients with and without 
Table 2 Baseline demographic, clinical, laboratory, and hemodynamic characteristics of the study population by PASP

\begin{tabular}{|c|c|c|c|c|c|}
\hline & All & PASP $\leq 35 \mathrm{mmHg}$ & $35 \mathrm{mmHg}<$ PASP $\leq 45 \mathrm{mmHg}$ & $45 \mathrm{mmHg}<$ PASP $\leq 60 \mathrm{mmHg}$ & PASP $>60 \mathrm{mmHg}$ \\
\hline No. of patients & 705 & 371 & 156 & 106 & 72 \\
\hline Age (years) & $48.12 \pm 15.02$ & $48.43 \pm 15.50$ & $45.50 \pm 14.08$ & $49.83 \pm 15.81$ & $49.71 \pm 12.63$ \\
\hline \multicolumn{6}{|l|}{ Gender } \\
\hline Male, n (\%) & 400 & $231(57.75 \%)$ & $73(18.25 \%)$ & $46(11.50 \%)$ & $40(10.00 \%)$ \\
\hline Female, n (\%) & 305 & $140(45.90 \%)$ & $83(27.21 \%)^{a}$ & $60(19.67 \%)^{a}$ & $32(10.49 \%)$ \\
\hline $\mathrm{BMI}\left(\mathrm{kg} / \mathrm{m}^{2}\right)$ & $22.32 \pm 4.45$ & $21.55 \pm 3.96$ & $22.98 \pm 4.94^{* *}$ & $22.47 \pm 4.39$ & $24.65 \pm 4.85^{* * *}$ \\
\hline \multicolumn{6}{|l|}{ Etiology of CKD, n (\%) } \\
\hline Glomerulonephritis & 481 & $268(55.72 \%)$ & $100(20.79 \%)$ & $69(14.35 \%)$ & $44(9.15 \%)$ \\
\hline Diabetic nephropathy & 104 & $45(43.27 \%)$ & $31(29.81 \%)^{b}$ & $17(16.35 \%)$ & $11(10.58 \%)$ \\
\hline Hypertensive nephropathy & 57 & $30(52.36 \%)$ & $13(22.81 \%)$ & $9(15.79 \%)$ & $5(8.77 \%)$ \\
\hline Lupus nephritis & 14 & $4(28.57 \%)$ & $0(0 \%)$ & $3(21.43 \%)$ & $7(50.00 \%)^{b}$ \\
\hline Polycystic kidney disease & 20 & $11(55.00 \%)$ & $6(30.00 \%)$ & $3(15.00 \%)$ & $0(0 \%)$ \\
\hline Others & 29 & $13(44.83 \%)$ & $6(20.69 \%)$ & $5(17.24 \%)$ & $5(17.24 \%)$ \\
\hline \multicolumn{6}{|l|}{ No. of anti-hypertensives } \\
\hline 0 anti-hypertensive & 72 & $41(56.94 \%)$ & $14(19.44 \%)$ & $9(12.50 \%)$ & $8(11.11 \%)$ \\
\hline 1 anti-hypertensives & 180 & $107(59.44 \%)$ & $28(15.56 \%)$ & $29(16.11 \%)$ & $16(8.89 \%)$ \\
\hline 2 anti-hypertensives & 230 & $132(57.39 \%)$ & $56(24.35 \%)$ & $22(9.57 \%)$ & $20(8.70 \%)$ \\
\hline 3 anti-hypertensives & 155 & $63(40.65 \%)$ & $39(25.16 \%)$ & $37(23.87 \%)$ & $16(10.32 \%)$ \\
\hline$\geq 4$ anti-hypertensives & 68 & $28(41.18 \%)$ & $19(27.94 \%)$ & $9(13.24 \%)$ & $12(17.65 \%)$ \\
\hline \multicolumn{6}{|l|}{ Other medications, n (\%) } \\
\hline Digoxin & 14 & $5(35.71 \%)$ & $0(0 \%)$ & $5(35.71 \%)$ & $4(28.57 \%)$ \\
\hline Warfarin & 26 & $5(19.23 \%)$ & $12(46.15 \%)$ & $5(19.23 \%)$ & $4(15.38 \%)$ \\
\hline Prostacyclins & 247 & $120(48.58 \%)$ & $55(22.27 \%)$ & $37(14.98 \%)$ & $35(14.17 \%)$ \\
\hline \multicolumn{6}{|l|}{ Laboratory tests } \\
\hline $\mathrm{Hb}(\mathrm{g} / \mathrm{L})$ & $94.19 \pm 23.46$ & $107.45 \pm 19.82$ & $80.37 \pm 19.50^{* * *}$ & $77.91 \pm 19.40^{* * *}$ & $81.37 \pm 12.77^{* * *}$ \\
\hline $\operatorname{ALB}(g / L)$ & $34.75 \pm 5.68$ & $35.44 \pm 5.11$ & $34.50 \pm 5.98$ & $33.15 \pm 6.92^{*}$ & $34.06 \pm 5.31$ \\
\hline $\mathrm{TC}(\mathrm{mmol} / \mathrm{L})$ & $4.37 \pm 1.16$ & $4.28 \pm 0.99$ & $4.43 \pm 1.58$ & $4.57 \pm 1.10$ & $4.38 \pm 0.93$ \\
\hline TG $(\mathrm{mmol} / \mathrm{L})$ & $1.68 \pm 1.10$ & $1.52 \pm 0.81$ & $1.90 \pm 1.50^{*}$ & $1.61 \pm 0.95$ & $2.13 \pm 1.43^{* *}$ \\
\hline Proteinuria (mg/24 h) & $1783.13 \pm 1233.31$ & $1176.14 \pm 971.05$ & $2132.18 \pm 1051.07^{* * *}$ & $2737.32 \pm 1372.09^{* * *}$ & $2749.72 \pm 687.34^{* * *}$ \\
\hline $\mathrm{Ca}(\mathrm{mmol} / \mathrm{L})$ & $2.17 \pm 0.19$ & $2.18 \pm 0.18$ & $2.17 \pm 0.20$ & $2.14 \pm 0.20$ & $2.21 \pm 0.20$ \\
\hline $\mathrm{P}(\mathrm{mmol} / \mathrm{L})$ & $1.41 \pm 0.52$ & $1.31 \pm 0.46$ & $1.51 \pm 0.53^{* * *}$ & $1.57 \pm 0.62^{* * *}$ & $1.43 \pm 0.55$ \\
\hline PTH (pg/ml) & $326.20 \pm 180.71$ & $266.02 \pm 148.51$ & $358.54 \pm 163.65^{* * *}$ & $353.40 \pm 154.59^{* * *}$ & $526.15 \pm 228.42^{* * *}$ \\
\hline Ferritin (ng/ml) & $350.27 \pm 192.52$ & $354.34 \pm 224.21$ & $301.23 \pm 142.90^{* *}$ & $370.56 \pm 146.29$ & $405.68 \pm 142.19$ \\
\hline $\mathrm{SI}(\mu \mathrm{mol} / \mathrm{L})$ & $12.38 \pm 5.62$ & $12.46 \pm 5.81$ & $13.05 \pm 6.51$ & $11.50 \pm 4.60$ & $11.83 \pm 3.35$ \\
\hline C3 (g/L) & $0.96 \pm 0.29$ & $1.01 \pm 0.33$ & $0.92 \pm 0.26^{* *}$ & $0.84 \pm 0.22^{* * *}$ & $0.95 \pm 0.21$ \\
\hline \multicolumn{6}{|l|}{ Hemodynamics } \\
\hline $\mathrm{SBP}(\mathrm{mmHg})$ & $141.24 \pm 14.14$ & $138.46 \pm 13.19$ & $143.71 \pm 16.22^{* *}$ & $145.53 \pm 14.98^{* * *}$ & $143.89 \pm 9.00^{* * *}$ \\
\hline DBP $(m m H g)$ & $85.44 \pm 9.80$ & $83.59 \pm 9.45$ & $87.28 \pm 10.89^{* *}$ & $88.49 \pm 10.08^{* * *}$ & $86.54 \pm 6.08^{* *}$ \\
\hline $\mathrm{eGFR}\left(\mathrm{ml} / \mathrm{min} / 1.73 \mathrm{~m}^{2}\right)$ & $33.55 \pm 32.51$ & $43.71 \pm 36.13$ & $22.84 \pm 25.27^{* * *}$ & $18.48 \pm 15.57^{* * *}$ & $26.57 \pm 27.29^{* * *}$ \\
\hline LVEF (\%) & $62.05 \pm 10.04$ & $63.50 \pm 9.33$ & $66.13 \pm 7.19^{* *}$ & $56.23 \pm 11.05^{* * *}$ & $54.26 \pm 9.66^{* * *}$ \\
\hline No. of dialysis patients (\%) & 331 & $136(36.66 \%)$ & $81(51.92 \%)$ & $66(62.26 \%)$ & $48(66.67 \%)$ \\
\hline Time of dialysis (months) & $16.89 \pm 14.16$ & $16.58 \pm 14.01$ & $15.54 \pm 11.42^{* * *}$ & $16.48 \pm 14.46^{* * *}$ & $20.29 \pm 17.64^{* * *}$ \\
\hline
\end{tabular}

PASP pulmonary artery systolic pressure, $C K D$ chronic kidney disease, $B M I$ body mass index, $A C E I$ angiotensin converting enzyme inhibitor, $A R B$ angiotensin receptor blocker, $C C B$ calcium channel blocker, $H b$ hemoglobin, $A L B$ albumin, $T C$ total cholesterol, $T G$ triglyceride, $P T H$ parathyroid hormone, SI serum iron, SBP systolic blood pressure, DBP diastolic blood pressure, eGFR estimated glomerular filtration rate, $L V E F$ left ventricular ejection fraction. Results are reported as means \pm standard deviation. Compared with non-PH group, ${ }^{*} p<0.05,{ }^{* *} p<0.01,{ }^{* * *} p<0.001 ;$ Compared with male group, ${ }^{\mathrm{a}} p<0.05$; Compared with glomerulonephritis group, ${ }^{\mathrm{b}} p<0.05$ 
Table 3 Multivariate ORs for prevalence of PH in CKD patients

\begin{tabular}{|c|c|c|}
\hline Determinants & OR $(95 \% \mathrm{Cl})$ & $P$-value \\
\hline Gender & $0.874(0.541-1.412)$ & 0.581 \\
\hline $\mathrm{BMI}\left(\mathrm{kg} / \mathrm{m}^{2}\right)$ & $1.070(1.011-1.133)$ & 0.020 \\
\hline Glomerulonephritis & reference & \\
\hline Diabetic nephropathy & $0.926(0.299-2.869)$ & 0.894 \\
\hline Hypertensive nephropathy & $1.589(0.451-5.597)$ & 0.471 \\
\hline Lupus nephritis & $0.542(0.141-2.078)$ & 0.372 \\
\hline Polycystic kidney disease & $1.335(0.137-13.056)$ & 0.804 \\
\hline Others & $0.753(0.128-4.438)$ & 0.754 \\
\hline $\mathrm{Hb}(\mathrm{g} / \mathrm{L})$ & $0.942(0.929-0.954)$ & 0.000 \\
\hline $\mathrm{ALB}(\mathrm{g} / \mathrm{L})$ & 1.017 (0.977-1.059) & 0.411 \\
\hline $\mathrm{TG}(\mathrm{mmol} / \mathrm{L})$ & $1.445(1.147-1.822)$ & 0.002 \\
\hline Proteinuria (mg/24 h) & $1.001(1.001-1.001)$ & 0.000 \\
\hline$P(\mathrm{mmol} / \mathrm{L})$ & $0.826(0.488-1.397)$ & 0.475 \\
\hline PTH (pg/ml) & $1.004(1.002-1.005)$ & 0.000 \\
\hline C3 (g/L) & $0.496(0.172-1.012)$ & 0.064 \\
\hline $\mathrm{SBP}(\mathrm{mmHg})$ & $1.003(0.982-1.024)$ & 0.785 \\
\hline $\mathrm{DBP}(\mathrm{mmHg})$ & $1.021(0.990-1.053)$ & 0.180 \\
\hline eGFR $\left(\mathrm{ml} / \mathrm{min} / 1.73 \mathrm{~m}^{2}\right)$ & $0.981(0.971-0.990)$ & 0.000 \\
\hline LVEF (\%) & $0.987(0.962-1.012)$ & 0.302 \\
\hline Time of dialysis (months) & $0.979(0.957-1.001)$ & 0.060 \\
\hline
\end{tabular}

$O R$ odds ratio, $\mathrm{Cl}$ confidence interval, $C K D$ chronic kidney disease, $B M I$ body mass index, $H b$ hemoglobin, $A L B$ albumin, $T G$ triglyceride, $P T H$ parathyroid hormone, SBP systolic blood pressure, DBP diastolic blood pressure, eGFR estimated glomerular filtration rate, LVEF left ventricular ejection fraction

$\mathrm{PH}$ were observed. Associated determinants of $\mathrm{PH}$ in our study have been noted to be the following: higher BMI, lower hemoglobin, albumin and complement 3 , increased TG, PTH and proteinuria, higher blood pressure, lower eGFR, lower LVEF and increased dialysis time. This implied that $\mathrm{PH}$ was determined by a diverse set of complex factors in CKD patients. Eventually, we found that BMI, hemoglobin, TG, proteinuria, PTH and eGFR were to be strongly associated with $\mathrm{PH}$. BMI as a surrogate of body composition is highly correlated with overweight, unhealthy lifestyle and abnormal metabolism [13]. Obesity is risk factor for the development of cardiovascular disease, diabetes mellitus, renal diseases and some others [14]. Therefore, Higher BMI has been used to predict renal dysfunction, hypertension and metabolic abnormalities [15]. According to our study, it also demonstrated a positive relationship between BMI and PH. It has been proved that severe anemia, an established cardiovascular risk factor in CKD, may extend its impact to pulmonary circulation. Low hemoglobin levels may contribute to $\mathrm{PH}$ by aggravating hypoxia triggered by concomitant conditions $[7,16]$. Right ventricular (RV) failure is the leading cause of death in $\mathrm{PH}$ and often progressed independent of the hemodynamic response to pulmonary vasodilators. Some researches have shown that circulating free fatty acids and long-chain acylcarnitines were significantly elevated in $\mathrm{PH}$ patients and increased in vivo myocardial triglyceride accumulation in $\mathrm{PH}$ [17]. Secondary hyperparathyroidism is a severe complication in CKD patients. Ulrich et al. reported that secondary hyperparathyroidism, which was not related to kidney disease but possibly to lower vitamin D status, was a risk factor for PH [18]. An elevated PTH level is associated with increased $\mathrm{N}$-terminal pro-brain natriuretic peptide, a marker of left ventricular wall stress, and increased risk of heart failure [19]. Genctoy G et al. also confirmed that secondary hyperparathyroidism was associated with $\mathrm{PH}$ in older patients with CKD and proteinuria [20]. Consistent with our findings, PTH could contribute to $\mathrm{PH}$ in $\mathrm{CKD}$ patients. Amounts of studies have proved that immune dysfunction involved in the pathogenesis of renal disease, including pro-inflammatory monocytes, mast-cell proliferation, T-lymphocyte dysfunction and decreased T-regulatory cells, et al [21-24]. An increase in circulating inflammatory mediators also causes an increase in oxidative stress resulting in endothelial dysfunction [25]. Proteinuria in CKD is also a predictor of endothelial dysfunction and has a direct relationship with cardiovascular mortality [20]. Based on the action of the combination of factors, glomeruli repeat injury and repair constantly, which led to renal function deterioration eventually. Interestingly, endothelial dysfunction is a main trigger of pulmonary hypertension.

To be mentioned, some factors were not independent determinants of $\mathrm{PH}$ in the present study, however, they might be considered a "warning". CKD is a progressive disease and involves alterations of etiologies, eg glomerulonephritis, diabetic nephropathy, hypertensive nephropathy, lupus nephritis, polycystic kidney disease, some of which associated with the prevalence of $\mathrm{PH}$. Hypertension and diabetes mellitus trigger left ventricular diastolic dysfunction, an alteration bound to increase pulmonary venous and arterial pressure $[3,26]$. In $\mathrm{PH}$ patients with systemic lupus erythematosus (SLE), macrophages, lymphocytes, antinuclear antibodies, and complement have been identified histologically in the pulmonary vasculature [27, 28]. Patients with diabetic nephropathy are more susceptible to mild $\mathrm{PH}$ and patients with lupus nephritis are more likely to suffer from severe $\mathrm{PH}$ compared to glomerulonephritis patients. The incidence of $\mathrm{PH}$ in patients with hypertensive nephropathy is not significantly increased due to well controlled blood pressure. In addition, the risk of $\mathrm{PH}$ in female patients is higher than male ones probably due to the serotonin, mutations in the bone morphogenetic protein receptor (BMPR) II gene, and estrogens [29].

In dialysis patients, the prevalence of $\mathrm{PH}$ was much higher, which had some specific risk factors for PH. In this study, patients with congenital heart failure and acute heart failure before had been excluded. However, 
subclinical heart failure was common in ESRD patients. The causes might include hypertension, salt and water overload, pleotropic effects of uraemic toxins and myocardial ischaemia. These factors were more prevalent in patients with $\mathrm{PH}$. Arteriovenous fistulae (AVF) are considered the gold standard for HD access [30]. They result in increased venous return with a concomitant increase in cardiac output and also lead to decreased systemic vascular resistances [3, 25]. Well-performed studies show that AVF flow and AVF duration are related independently to the severity of pulmonary hypertension in HD patients [31]. In a study of patients receiving $\mathrm{PD}, \mathrm{LV}$ mass index, alongside low serum albumin and fluid overload, was a predictor of $\mathrm{PH}$ in a multivariate model [32].

Our study still has several potential limitations. First, the diagnosis of $\mathrm{PH}$ was only based on echocardiography without right-sided heart catheterization (RHC), the gold standard diagnostic tool, to confirm the echocardiographic findings. Second, not all the CKD patients from July 2013 to September 2015 were enrolled in the study because some of them lacked the data of echocardiography. Third, the follow-up data to evaluate the effect of $\mathrm{PH}$ on morbidity and mortality were not available due to the retrospective study. Finally, this was a single center study. More data of multi-center needed to be included in to confirm the conclusions.

\section{Conclusions}

Based on our study, it confirms that the prevalence of $\mathrm{PH}$ is increased with the deterioration of renal function, however, which has no direct relation to the severity of $\mathrm{PH}$. $\mathrm{PH}$ occurs with more frequency in dialysis patients. However, it has no difference in the overall prevalence of $\mathrm{PH}$ between HD and PD patients. PH is determined by a diverse set of complex factors including BMI, hemoglobin, TG, proteinuria, PTH and eGFR in CKD patients. Therefore, higher BMI and TG, more sever anemia, proteinuria and secondary hyperparathyroidism, poor renal dysfunction predict the more prevalence of PH. Females, lupus nephritis and diabetic nephropathy could be considered as a "warning". On the other hand, our findings further the epidemiology profile of $\mathrm{PH}$ across the spectrum of CKD.

\footnotetext{
Abbreviations

AVF: Arteriovenous fistulae; BMI: Body mass index; BMPR: Bone morphogenetic protein receptor; CKD: Chronic kidney disease; eGFR: Estimated glomerular filtration rate; ESRD: End-stage renal disease; HD: Hemodialysis; LVEF: Left ventricular ejection fraction; PAP: Pulmonary arterial pressure; PASP: Pulmonary artery systolic pressure; PD: Peritoneal dialysis; PH: Pulmonary hypertension; PTH: Parathyroid hormone; PVR: Pulmonary vascular resistance; RHC: Right-sided heart catheterization; RV: Right ventricular; SD: Standard deviation; SLE: Systemic lupus erythematosus; TG: Triglyceride
}

Funding

This work was supported by Grants (No.81500546) from National Natural Science Foundation of China.

\section{Availability of data and materials}

All data generated or analyzed during this study are included in this published article. The datasets analyzed during the current study are available from the corresponding author on reasonable request.

\section{Authors' contributions}

QZ had full access to all of the data in the study and takes responsibility for the integrity of the data and the accuracy of the data analysis. QZ and YH contributed substantially to the study design, data analysis and interpretation, and the writing of the manuscript. $\mathrm{HZ}$, YL and $\mathrm{YH}$ contributed to data interpretation and critical revision. All authors read and approved the manuscript.

\section{Ethics approval and consent to participate}

The Ethics Research Committee at Tongji Hospital approved the study and agreed that informed consent was not necessary because of the

observational nature (retrospective analysis) of this study. The information of all patients was anonymized and de-identified prior to analysis.

Consent for publication

Not applicable.

Competing interests

The authors declare that they have no competing interests.

\section{Publisher's Note}

Springer Nature remains neutral with regard to jurisdictional claims in published maps and institutional affiliations.

Received: 10 April 2017 Accepted: 7 March 2018

Published online: 20 March 2018

References

1. Vonk-Noordegraaf A, Souza R. Cardiac magnetic resonance imaging: what can it add to our knowledge of the right ventricle in pulmonary arterial hypertension? Am J Cardiol. 2012;110(6 Suppl):25S-31S.

2. Sharma M, Pinnamaneni S, Aronow WS, Jozwik B, Frishman WH. Existing drugs and agents under investigation for pulmonary arterial hypertension. Cardiol Rev. 2014;22(6):297-305.

3. Bolignano D, Rastelli S, Agarwal R, Fliser D, Massy Z, Ortiz A, Wiecek A, Martinez-Castelao A, Covic A, Goldsmith D, et al. Pulmonary hypertension in CKD. Am J Kidney Dis. 2013;61(4):612-22.

4. Haddad F, Fuh E, Peterson T, Skhiri M, Kudelko KT, De Jesus PV, Winkelmayer WC, Doyle RL, Chertow GM, Zamanian RT. Incidence, correlates, and consequences of acute kidney injury in patients with pulmonary arterial hypertension hospitalized with acute right-side heart failure. J Card Fail. 2011;17(7):533-9.

5. Rudski LG, Lai WW, Afilalo J, Hua L, Handschumacher MD, Chandrasekaran K, Solomon SD, Louie EK, Schiller NB. Guidelines for the echocardiographic assessment of the right heart in adults: a report from the American Society of Echocardiography endorsed by the European Association of

Echocardiography, a registered branch of the European Society of Cardiology, and the Canadian Society of Echocardiography. J Am Soc Echocardiogr. 2010; 23(7):685-713. 786-788

6. Berger M, Haimowitz A, Van Tosh A, Berdoff RL, Goldberg E. Quantitative assessment of pulmonary hypertension in patients with tricuspid regurgitation using continuous wave Doppler ultrasound. J Am Coll Cardiol. 1985;6(2):359-65.

7. Buemi M, Senatore M, Gallo GC, Crasci E, Campo S, Sturiale A, Coppolino G, Bolignano D, Frisina N. Pulmonary hypertension and erythropoietin. Kidney Blood Press Res. 2007:30(4):248-52.

8. McQuillan BM, Picard MH, Leavitt M, Weyman AE. Clinical correlates and reference intervals for pulmonary artery systolic pressure among echocardiographically normal subjects. Circulation. 2001;104(23):2797-802.

9. Schiller NB. Pulmonary artery pressure estimation by Doppler and twodimensional echocardiography. Cardiol Clin. 1990;8(2):277-87.

10. Patel R, Aronow WS, Patel L, Gandhi K, Desai H, Kaul D, Sahgal SP. Treatment of pulmonary hypertension. Med Sci Monit. 2012;18(4):A31-9. 
11. Chin KM, Rubin LJ. Pulmonary arterial hypertension. J Am Coll Cardiol. 2008; 51(16):1527-38.

12. Li Z, Liang X, Liu S, Ye Z, Chen Y, Wang W, Li R, Xu L, Feng Z, Shi W. Pulmonary hypertension: epidemiology in different CKD stages and its association with cardiovascular morbidity. PLoS One. 2014;9(12):e114392.

13. Walther D, Curjuric I, Dratva J, Schaffner E, Quinto C, Schmidt-Trucksass A, Eze IC, Burdet L, Pons M, Gerbase MW, et al. Hypertension, diabetes and lifestyle in the long-term - results from a Swiss population-based cohort. Prev Med. 2017;97:56-61.

14. Brida M, Dimopoulos K, Kempny A, Liodakis E, Alonso-Gonzalez R, Swan L, Uebing A, Baumgartner H, Gatzoulis MA, Diller GP. Body mass index in adult congenital heart disease. Heart. 2017;103(16):1250-1257.

15. Cohen E, Fraser A, Goldberg E, Milo G, Garty M, Krause I. Association between the body mass index and chronic kidney disease in men and women. A population-based study from Israel. Nephrol Dial Transplant. 2013;28(Suppl 4):v130-5.

16. van Loon RL, Bartelds B, Wagener FA, Affara N, Mohaupt S, Wijnberg H, Pennings SW, Takens J, Berger RM. Erythropoietin attenuates pulmonary vascular remodeling in experimental pulmonary arterial hypertension through interplay between endothelial progenitor cells and Heme oxygenase. Front Pediatr. 2015;3:71.

17. Brittain EL, Talati M, Fessel JP, Zhu H, Penner N, Calcutt MW, West JD, Funke $M$, Lewis GD, Gerszten RE, et al. Fatty acid metabolic defects and right ventricular lipotoxicity in human pulmonary arterial hypertension Circulation. 2016;133(20):1936-44.

18. Ulrich S, Hersberger M, Fischler M, Huber LC, Senn O, Treder U, Speich R Schmid C. Bone mineral density and secondary hyperparathyroidism in pulmonary hypertension. Open Respir Med J. 2009;3:53-60.

19. Wannamethee SG, Welsh P, Papacosta O, Lennon L, Whincup PH, Sattar N Elevated parathyroid hormone, but not vitamin $\mathrm{D}$ deficiency, is associated with increased risk of heart failure in older men with and without cardiovascular disease. Circ Heart Fail. 2014;7(5):732-9.

20. Genctoy G, Arikan S, Gedik O. Secondary hyperparathyroidism is associated with pulmonary hypertension in older patients with chronic kidney disease and proteinuria. Int Urol Nephrol. 2015;47(2):353-8.

21. Betjes MG. Immune cell dysfunction and inflammation in end-stage renal disease. Nat Rev Nephrol. 2013;9(5):255-65.

22. Schepers E, Houthuys E, Dhondt A, De Meyer G, Neirynck N, Bernaert P, Van den Bergh R, Brouckaert P, Vanholder R, Glorieux G. Transcriptome analysis in patients with chronic kidney disease on hemodialysis disclosing a key role for CD16+CX3CR1+ monocytes. PLoS One. 2015;10(4):e121750.

23. Eller K, Wolf D, Huber JM, Metz M, Mayer G, McKenzie AN, Maurer M, Rosenkranz AR, Wolf AM. IL-9 production by regulatory T cells recruits mast cells that are essential for regulatory $T$ cell-induced immune suppression. J Immunol. 2011:186(1):83-91.

24. Swaminathan S, Shah SV. Novel inflammatory mechanisms of accelerated atherosclerosis in kidney disease. Kidney Int. 2011;80(5):453-63.

25. Kawar B, Ellam T, Jackson C, Kiely DG. Pulmonary hypertension in renal disease: epidemiology, potential mechanisms and implications. Am J Nephrol. 2013;37(3):281-90.

26. Tiengo A, Fadini GP, Avogaro A. The metabolic syndrome, diabetes and lung dysfunction. Diabetes Metab. 2008;34(5):447-54.

27. Jais X, Launay D, Yaici A, Le Pavec J, Tcherakian C, Sitbon O, Simonneau G, Humbert M. Immunosuppressive therapy in lupus- and mixed connective tissue disease-associated pulmonary arterial hypertension: a retrospective analysis of twenty-three cases. Arthritis Rheum. 2008;58(2):521-31.

28. Mensah KA, Yadav R, Trow TK, Brunet CM, Fares WH. Lupus-associated pulmonary arterial hypertension: variable course and importance of prompt recognition. Case Rep Med. 2015;2015:328435.

29. Wallace E, Morrell NW, Yang XD, Long L, Stevens H, Nilsen M, Loughlin L, Mair KM, Baker AH, MacLean MR. A sex-specific MicroRNA-96/5-Hydroxytryptamine 1B Axis influences development of pulmonary hypertension. Am J Respir Crit Care Med. 2015;191(12):1432-42.

30. National Kidney Foundation. K/DOQI clinical practice guidelines for chronic kidney disease: evaluation, classification, and stratification. Am J Kidney Dis. 2002;39(2 Suppl 1):S1-S266

31. Abdelwhab S, Elshinnawy S. Pulmonary hypertension in chronic renal failure patients. Am J Nephrol. 2008;28(6):990-7.

32. Unal A, Sipahioglu M, Oguz F, Kaya M, Kucuk H, Tokgoz B, Buyukoglan H, Oymak O, Utas C. Pulmonary hypertension in peritoneal dialysis patients: prevalence and risk factors. Perit Dial Int. 2009;29(2):191-8.

\section{Submit your next manuscript to BioMed Central and we will help you at every step:}

- We accept pre-submission inquiries

- Our selector tool helps you to find the most relevant journal

- We provide round the clock customer support

- Convenient online submission

- Thorough peer review

- Inclusion in PubMed and all major indexing services

- Maximum visibility for your research

Submit your manuscript at www.biomedcentral.com/submit
Biomed Central 